\title{
The theory of modern dress style of art and design form
}

\author{
Wang hui ${ }^{1, a}$ \\ ${ }^{1}$ Jiangxi Institute of Fashion Technology, Jiangxi, Nanchang, 330201 \\ a35554229@qq.com
}

Keywords: The dress; Art style; Design form; The development of

\begin{abstract}
With the rapid development of society, economy, culture and lifestyle changes. The function of the modern garment packing garments are not limited to the human body, it is a form of human minds. The demand for clothing is also more and more people, about style and form of changes are also continuously improve the aesthetic. This paper first expounds the background of the ceremonial dress, combing the status quo of the dress in the contemporary, and for the dress style of art and design variable forms of diversity are analyzed and integrated. Focused on its features and the mutual transformation relationship, dress style, color, fabric and the importance of consumer psychology. Finally tells the story of this graduation design train of thought, its artistic style and design form integral used in the dress.
\end{abstract}

\section{The introduction}

Tell us about the different style characteristics through different angles, thus will converge to form new element, make the style of the dress and the design more diversification. From the contemporary situation analysis, the development of China in recent years, the increasing of people's living standard, prompted the rapid development of domestic clothing, dress also follow the fashion trends. Element with the improvement of China in the international status, China has become the latest must-haves in the clothing design, how to apply Chinese elements better dress in at the end of the paper is about a chapter. The development trend of future dress also need designers continue to work hard to create a better work, to meet the market demand.

\section{The artistic style of the dress}

Generalized the artistic style of art is the artist or some defined groups formed in activity using the relative stability of artistic style, quality, style and air. It is the embodiment of the artists of different creative personality, contents, patterns, and artistic works contains thinking and artistic unity. In this art style refers to the clothing style, also is the reflection of art style in clothing. In the book "fashion design", written by xiao-gang liu pointed out that in the modern fashion design, to separate clothing style has the very vital significance. Product sales in the market, the division of the style of clothing is the clothing categories, can be more convenient in production and sales, more accord with the demands of consumers and the interests of the highest effect. Can be seen from Mr Xiao-gang liu text in the expression of the artistic style of clothing to locate the significance of its relationship with the consumer with a preference for individual be fond of, determine the sales direction and development.

Art style element is the clothing fabrics, color, outline shape and materials, an element of split eventually applied to the basic form of the costume design. Classical style, it is to point to draw lessons from ancient European style, and conveys has the charm of elegant temperament. A style of the main is $X$, and more use the beautification clothing, such as bustle, breast pad shape with a special focus on women's three-dimensional shape, decoration and various, lace and silk fabric is more frequently used. Romantic style, the formation of the main style of evolved from evening dress, reflects the women's gentle, multi-purpose and fluent line in shape, decorated with lace, embroidery and so on, the choice of fabrics are also more gentle, like bud silk, silk, romantic amorous feelings. Luxuriant style: often appeared in the haute couture dress, the whole clothes do manual work is delicate, multiple-choice gloss, good fabric, use more is hand embroidery, all kinds of technological means such as figure, falbala, with pearls, form the three-dimensional effect, looks 
noble gorgeous. Hale style: simple lines, simple features, USES the most were surface shape and body shape, not too much decoration, choose the fabric texture is thick, make dress partial neutral. Avant-garde style: mainly influenced by the thoughts of the postmodern art, modelling is more strange, use more is asymmetric structure, local modelling hyperbole, emphasize contrast effect, the pursuit of a kind of novel design, is the style of strong personality. In integral style ways, started by the elegant classical $20 \mathrm{~s}$ to noble and free from vulgarity in the $50 \mathrm{~s}$, to the active and open is the mainstream of fashion in the $80 \mathrm{~s}$. And now many designers will dress as a new hobby, design combination of popular elements, created a more modern dress, such as: fashion dress, free style dress, national dress, etc. Depending on the region, the style of dress in a different country also deduce different types, such as Japanese, Korean and Chinese.

\section{In the form of dress design}

The main content of design form. Design elements are the basic unit in the design, according to different industries have different design elements, and design elements are different for different design style, design form. Ceremonial dress is between people wore clothes in social situations, but what is the essential difference between the dress according to the wearing time points, can be divided into two categories: day wedding dress and evening dress.

Day dress (day dress) of different have different ways of dress, women can choose to have different design and color of dress, or a handmade suits, very elegant and chic two suits, etc. Traditional dress color monotone, which is more formal, black black at formal celebrations such as grand occasion can show most solemn and atmosphere. But in a friend's birthday party, opening ceremony, the atmosphere is lively, then dress color will be more bright.

Evening dress formal dress usually dress is in the evening, mostly appeared in the dinner, dance and other formal occasions. Evening dress is formal dress, in the classification of all dress is the most characteristic, the most can show female charm of clothing. Evening dress is used for communication at night because it is over, so choose the fabric is organza, bud more flash, noble and gorgeous fabric. Color options is more elegant, deserve to go up in consistent with clothing color sequined, embroidered beads, magnificent diamonds and so on, all show the elegant evening dress, and free from vulgarity.

Cocktail dress (dress, half a formal dress) to 6 PM usually, guest friend exchanges between informal dress dress, because of the different occasions, generally do not prepare too much seat, mostly stand eating and talking. On such occasions, therefore, women's dresses tend to choose the design of short and hard working. There are a lot of can be used in a cocktail dress fabrics, such as the natural pure silk, brocade, blending, worsted fabrics, etc., now there are more and more new types of fabrics used in dress.

Wedding dress (dress) white dress first pass from the west, more used to get married, is a favorite of all women. White represents the pure and holy. Wedding dress make more for the fabric is silk, thin organza, lace, etc. Will use some polyester satin, in terms of modelling, shandong silk, brocade, etc to fold, handmade flowers. Craft decorations, make more is hand sewing, embroidery, drawnwork, cutwork hollow out, collage, and Mosaic technique, the production of fine craft to make dress more rich stereo feeling, aesthetic feeling more.

The classification of the design form and use. There are many kinds of the design of the dress form classification, according to the dress style to have a strapless style, with big scoop-back design, single straps neck, etc.; Points according to the outline shape have A type and $\mathrm{H}$ type, bitter fleabane bitter fleabane skirt, fish, etc. For dress get model is the key to a successful about design, it occupies the important position of the design of dress, round collar, the collar and lead, collar, $\mathrm{V}$ collar, heart-shaped collar, boat (arc), neck hung led, irregular get model is the most commonly used "collar modelling; Back in dress design modelling is changeful, v-shaped, u-shaped, round collar line, more exaggerated is back above all show the charm of the human body wearing large area; Whether the model of traditional or modern modelling, the design of the two shoulder is an important detail, perfect the design of the integral style of the dress can be better. Shoulder in modern dress design can be alone again, change the shape, but the actual mostly according to the 
whole modelling style of dress design. In the dress skirt also occupy the important position, the earliest start in the medieval western traditional dress. A strip fixed in the back of the dress is the dress of the fabrics of rectangle, can also is by the skirt is placed at the back of the skirt to mop the floor on the ground type, from the shoulders down, combined with the shoulder modelling, some can also be started with the head, connected to the yarn to the ground form a longer more beautiful style. In general, the wedding dress can be all kinds of skirt drag, foil in the wedding dress integral aesthetic feeling.

\section{Design form and artistic style}

The relationship between the design form and artistic style. In the design of the clothing design style is becoming more and more mature now, there are many new ways and methods, style conversion between fusion is a kind of very good method. Clothing style transformation is combining the style of clothing elements constitute a new style element, showing different mental connotation. Dress is composed of three elements such as form, color, material, through mutual collocation to form a new style elements, show different positioning means, dress transformation of fusion are embodied in this way.

Design form and artistic style. With the advancing of the society, to refine style classification, for every consumer to see the specific location, can attract more consumer groups. Can with the popular trend in different stages of the evolution of the positioning of its own brand style, the adjustment and transformation to happen, the more the love of consumers, this method is also current ways to design a new lease on life. To develop it cannot stand still. Have a plenty of the corresponding to each other in the style of dress, such as the modern and traditional styles; Have a plenty of nearby, such as national and traditional style. Communication between the corresponding style dress, also can make the dress style show the new look, in a single style to join adjacent style elements can form a different kind of theme, style of individual accounts for a larger proportion overall characteristics would prefer to share larger style. Traditional elements combined with national element, which constitutes a new style elements, basic is lay particular stress on national traditional dress styles, adjacent or conversion between the corresponding style characteristics, are defined in a style of increase and decrease, under the condition of equilibrium and can become another kind of new style, the style of this transformation will form the new style of intermediate type.

\section{The trend of the dress and evolution}

The promising prospects of dress development in China, and mainly because of China's dress market gradually development and the improvement of people's life quality, and consumer demand, and so on, these factors have helped dress industry has entered a new era. In addition, with the improvement of China's economic power, economy, culture and politics are in line with the world, more and more popular information and trends can be hand, then combined with traditional Chinese culture, a new trend of clothing, Chinese culture in the use of more and more, and the world, the western elements in the eastern clothing, at the same time, Chinese elements are also affects the development of world clothing, the design of dress also follow the trend, make the ancient and the integration of the future elements, complementary shortcomings develop strengths make the perfect mix of eastern and western cultures reflected in the clothing, dress, too.

Other designers should be more innovative consciousness, innovative spirit and innovative ability, in the process of product development design designers can play a greater role. Development of increasingly powerful China makes the Chinese elements of more and more used in international dress, decorative pattern, the embroidery of totem, the innovation of decorative arts, to enrich the style of dress. Hope to dress in the future development road more diversification, personalization, nationalization, costliness, and science and technology, the development direction of more also need we continue to explore and research, combined with the latest fashion innovation more dress is the focus of the present design. Also want to dress in the future path of development will become better and better. 


\section{Reference}

[1] Yingmei Tang. Theory of contemporary Chinese art and traditional national style in the design of fusion [J]. Journal of shaoyang college, 2006 (4).

[2] Zhongqi Zhang. Peony patterns in the women dress application [J]. Journal of international textile review, 2014 (10).

[3] Liu yang. Chinese style clothing art design research [J]. Journal of digital fashion (new visual arts), 2012 (3). 